http://jmscr.igmpublication.org/home/ ISSN (e)-2347-176x ISSN (p) 2455-0450 crossref DOI: https://dx.doi.org/10.18535/jmscr/v8i2.50

\title{
Hypothyroidism and its Associations- An Observational Study in North India
}

Authors

Shadab Samad ${ }^{1}$, Sunil Kumar Gupta ${ }^{2 *}$, Maaz Ozair ${ }^{3}$, Ashvanee Kumar ${ }^{4}$, Waseem Ramzan Dar ${ }^{5}$, Uday Joshi ${ }^{6}$, Arun Kumar ${ }^{7}$

${ }^{1,3,4}$ Assistant Professor, Department of Medicine, G S Medical college and Hospital, Hapur ,U.P., India 245304

${ }^{2}$ Associate Professor, Department of Medicine, G S Medical college and Hospital, N.H. 24, Pilkhuwa ,Hapur U.P., India 245304

${ }^{5,6,7}$ Senior Resident, Department of Medicine G S Medical College and Hospital, N.H. 24, Pilkhuwa, Hapur U.P., India 245304

*Corresponding Author

Dr Sunil Kumar Gupta

Associate Professor, Department of Medicine, S Medical College and Hospital, Hapur, U.P., India 245304

\begin{abstract}
Hypothyroidism has broad clinical with high prevalence in Indian population. Hypothyroidism has been associated with many co morbid clinical conditions. Current Study conducted as retrospective study using data of newly diagnosed hypothyroid patients collected from outpatient department of Medicine. Study results showed that Female patients were in higher number than males. A total of $46 \%$ patients were overweight and $33.3 \%$ patients were obese. $58 \%$ patients presented with fatigue which was the commonest symptom among patients. Thyroid swelling was observed in $40 \%$ of participants. Menstrual abnormalities were reported by $80 \%$ female participants. Female participants had lower mean systolic blood pressure than male participants. Overall TSH level among all patients was $24.6 \pm 32.5 \mathrm{mIU} / \mathrm{L}$. Subclinical hypothyroidism was found in 16\% patients. Female patients had higher mean TSH as compared to males. $10.6 \%$ of patients were diagnosed to be suffering with Diabetes Mellitus. The current Study concludes that Hypothyroid patients should be evaluated for other co morbid associations for better patient management and outcome.
\end{abstract}

\section{Introduction}

Hypothyroidism is a broad clinical spectrum ranging from an overt myxoedema to an asymptomatic or subclinical condition with normal levels. The prevalence of hypothyroidism in the developed world is about $4-5 \%$. The prevalence of subclinical hypothyroidism in the developed world is about $4-15 \% .{ }^{[1],[2]}$ Projection from various studies suggest that approximately 42 million people in
India suffer from thyroid diseases. ${ }^{[3]}$ Prevalence of hypothyroidism in the overall Indian study population was $10.95 \% .{ }^{[4]}$ Females were significantly higher in proportion than males. ${ }^{[4]}$ Hypothyroidism contributes to cardiovascular morbidity by enhancing other risk factors like hyperlipidemia and hypertension. ${ }^{[5]}$ Hypothyroidism has also been associated with nonalcoholic fatty liver disease, cancer mortality, arthritis, and kidney dysfunction but the casualty in these situations is 
controversial. ${ }^{[6]}$ Looking at hypothyroidism as one of the prevalent clinical condition, its proven effects on pathophysiology of other disorders, its associations need to be evaluated. Present study aims to find epidemiology of hypothyroidism and its associations in north Indian state, Utter Pradesh.

\section{Materials and Methods}

Study was conducted in the Department of Medicine, G S Medical College \& Hospital. Data of patients reporting in the Out Patients Department of Medicine were included in the study. Newly diagnosed patients and treatment naive with both clinical and subclinical hypothyroidism were included. Patients associated with Pregnancy, Chronic Liver or Kidney disease, on drugs affecting thyroid physiology and post thyroid surgery or ablation was excluded. Study was retrospective, observational cross sectional with sample size of 150 patients and study period of 4 months. Data was collected retrospectively from outpatient department of medicine. Statistical analysis was done by appropriate statistical test with the help of SPSS software 23 version.

\section{Results}

Data of 150 newly diagnosed patients with hypothyroidism was collected from the outpatient department. Their clinical reports and required parameters were noted and analysis was done.

\section{Sex Distribution:}

Out of total 150 patients, 107 (71.3\%) patients were females and 43 (28.7\%) were males. Overall mean age of all patients was 33.02 with $\mathrm{SD} \pm 14.39$ years. Mean age of females was less as compared to males.

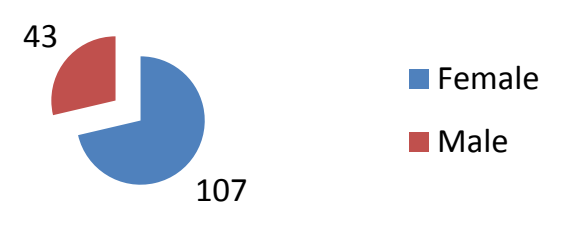

Figure 1 Sex distribution

\section{BMI}

Mean calculated BMI of participants was $25.9 \pm 6.1$ $\mathrm{kg} / \mathrm{m}^{2}$. Gender analysis of BMI revealed that males had slightly higher mean BMI 24.6 \pm 3.6 as compared to females who had mean BMI of $24.4 \pm 4.4 \mathrm{~kg} / \mathrm{m}^{2}$.A total of $69(46 \%)$ patients were overweight and $50(33.3 \%)$ patients were obese. Cut-offs for overweight (BMI $\geq 23.0 \mathrm{~kg} / \mathrm{m} 2$ ) and obesity (BMI $\geq 25.0 \mathrm{~kg} / \mathrm{m} 2$ ) were taken. ${ }^{[7]}$

\section{Symptoms}

$87(58 \%)$ patients presented with fatigue which was the commonest symptom among patients. Menstrual abnormalities were reported by 86 (80\%) female participants and amongst menstrual abnormalities, menorrhagia (72\%) was the most common symptom followed by irregular menstrual cycle. No post menopausal women reported abnormal vaginal bleeding. Thyroid swelling was observed in $40 \%$ of participants while $18(12 \%)$ had complaint of constipation and $10(6.6 \%)$ of patients had Hoarseness of voice.

Table 1 Presenting Symptoms

\begin{tabular}{|l|c|}
\hline Symptom & Patient $\%$ \\
\hline Fatigue & $87 \%$ \\
\hline Weight gain & $56 \%$ \\
\hline Irregular menstruation & $57.30 \%$ \\
\hline Thyroid swelling & $40 \%$ \\
\hline Constipation & $18 \%$ \\
\hline Feeling cold & $22 \%$ \\
\hline Hoarseness of voice & $12 \%$ \\
\hline
\end{tabular}

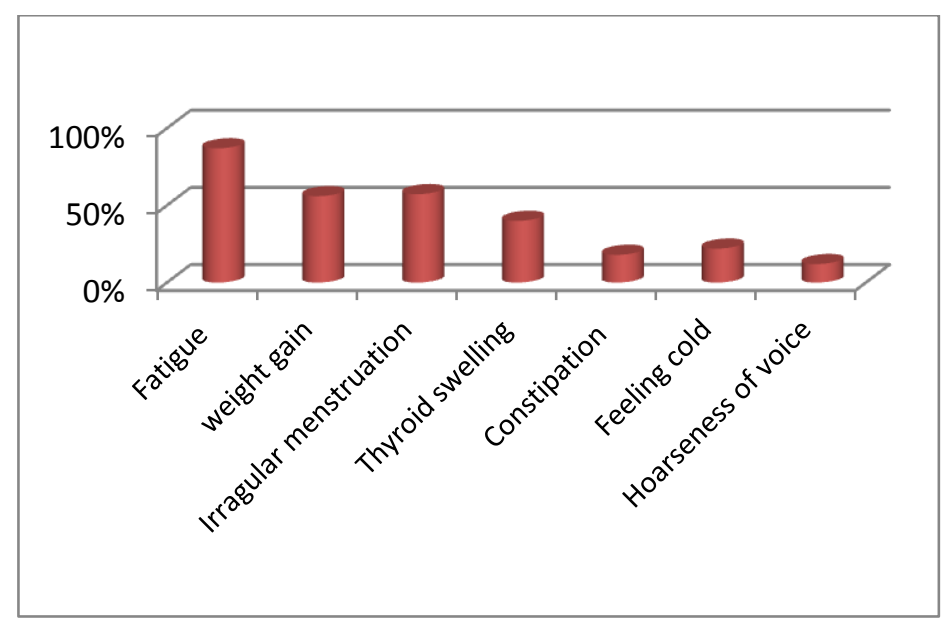

Figure 2 - Presenting Symptoms 


\section{Blood pressure}

Mean systolic blood pressure recorded amongst participants was $125.9 \pm 15.3 \mathrm{mmHg}$. Gender analysis of systolic blood pressure revealed that the female participants had mean systolic blood pressure of $123.5 \pm 12.4 \mathrm{mmHg}$ while the male participants had mean systolic blood pressure of $131.9 \pm 19.5 \mathrm{mmHg}$.

Participants of $\geq 40$ year age had mean SBP of $138.36 \pm 16.86 \mathrm{mmHg}$. Males above 40 years had mean SBP $149 \pm 18.66 \mathrm{mmHg}$ whereas females of the same age group had mean SBP $138.36 \pm 16.86$ $\mathrm{mm} \mathrm{Hg}$, which is statistically significant with $\mathrm{p}=$ 0.015 .

Mean diastolic pressure in all participants was 78.3 $\pm 10.6 \mathrm{mmHg}$.Mean diastolic pressure among males was $80 \pm 12.2 \mathrm{mmHg}$ whereas among females it was $77 \pm 13.2 \mathrm{mmHg}$. Mean diastolic pressure among all patients above 40 years was $88.6 \pm 11.6 \mathrm{mmHg}$.

\section{Thyroid profile}

Overall TSH level among all patients was 24.6 $\pm 32.5 \mathrm{mIU} / \mathrm{L}$. Subclinical hypothyroidism was found in $16 \%$ patients. Female patients had higher mean TSH $28.19 \pm 29.8 \mathrm{mIU} / \mathrm{L}$ as compared to males with mean TSH $22.6 \pm 24.3 \mathrm{mIU} / \mathrm{L}$, which is statistically in- significant with $\mathrm{p}$ value 0.328 .

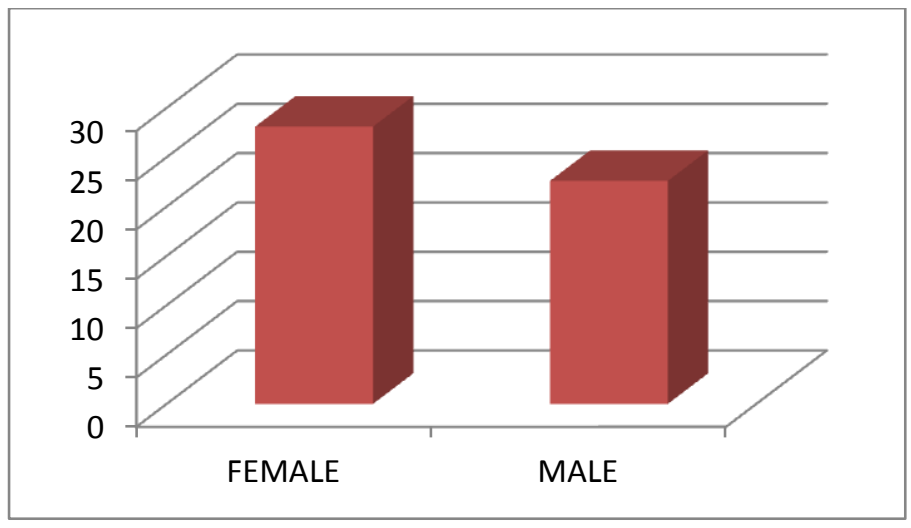

Figure 2 - TSH (mIU/L)

\section{Diabetic profile}

Mean fasting blood sugar of participants was 94.2 $\pm 12.1 \mathrm{mg} \% .16(10.6 \%)$ of patients were diagnosed to be suffering from Diabetes Mellitus. All diagnosed diabetic patients were more than 35 years of age. 4 patients were on insulin therapy along with oral hypoglycaemic drugs. Diabetes was found to be more prevalent in males than females (10 vs 6 patients). Glycosylated haemoglobin could be done in 10 patients and was found to be 9.4 in females and 9.7 among males which is statistically insignificant with $\mathrm{p}$ value 0.405 .

On correlating the BMI and TSH value, weakly positive correlation found between two parameters with correlation coefficient 0.19 and $p$ value 0.59 .

\section{Discussion}

Hypothyroidism is one of the common endocrine disorders prevalent in population. Its ability to remain undiagnosed and its non specific symptoms give it a peculiar but important clinical entity. Prevalence of hypothyroidism in India, in earlier studies was found to be $10.05 \%$ in the general population. ${ }^{[4]}$ Study conducted by Usha Menon Vet al. in eight cities of India found $8.02 \%$ prevalence of subclinical hypothyroidism $(\mathrm{SCH}) .{ }^{[8]}$

In our study we found that females were more affected than males in ratio of approximate 2.5:1 ,which is consistent with other epidemiological findings. ${ }^{[9],[10]}$. Current study also points towards lower mean age of females than affected males. Mean calculated BMI of participants was $25.9 \pm 6.1 \mathrm{~kg} / \mathrm{m} 2$ with male participants having slightly higher BMI than Females which is statistically not significant with $\mathrm{p}$ value $>0.05$. Overall $46 \%$ participants were overweight and approximately $33 \%$ participants were obese. Our Study also found weak positive correlation between BMI and TSH levels. Study by Xu,R. ${ }^{[11]}$ on Chinese population did not find correlation between $\mathrm{TSH}$ level and BMI but thyroid hormonal level(T3 andT4) and BMI were correlated in their study ${ }^{\mathrm{i}}$ conflicting to this Meng $\mathrm{Z}$ et al. ${ }^{[12]}$, [found TSH level to correlated to BMI.

Fatigue was found to be the most common symptom (58\%) among study participants similar to study by Sethi $\mathrm{B}$ et $\mathrm{al}^{[13]}$ on Indian population suggesting the metabolic effect of thyroid gland dysfunction. Similar finding was also found by Delemer et $\mathrm{al}^{[14]}$. This highlights the importance of this non specific symptom in terms of hypothyroidism. 
Approximately $80 \%$ of females in the study group had menstrual cycle related complaints. These points to the relevance of thyroid status among females presenting with menstrual related complaints. Our study also found large number of clinical thyroid swelling (40\%) among participants. Mean blood pressure of female participants was lower than males. On further analysis, participantsas expected over 40 year of age had significantly higher blood pressure. Males over 40 years had significantly higher blood pressure than females over 40 years with $p$ value $<0.05$. No correlation was found between mean BP and TSH levels. Nair A et al in their study based in south India found average systolic and diastolic BP being $131 \pm 18$ and $77 \pm 8.8 \mathrm{~mm}$ of $\mathrm{Hg}$ respectively and $58.2 \%$ persons had a systolic BP more than $130 \mathrm{~mm}$ of $\mathrm{Hg}$, and 14.9 patients had a diastolic BP above $90 \mathrm{~mm}$ of $\mathrm{Hg}^{[15]}$

Current study revealed mean fasting blood sugar of participants as $94.2 \pm 12.1 \mathrm{mg} \%$ with Diabetes diagnosed in $10.6 \%$ of patients and males more commonly affected. Studies have documented a higher than normal prevalence of thyroid dysfunction. $12.3 \%$ prevalence of thyroid dysfunction was reported among Greek diabetic patients $^{[16]}$ and $16 \%$ of Saudi patients with type 2 diabetes were found to have thyroid dysfunction ${ }^{[17]}$. Overall TSH level among all patients was 24.6 \pm 32.5 . Subclinical hypothyroidism was found among $16 \%$ patients as compared to $9.4 \%$ found by Unnikrishnan AG et al in their study in India. ${ }^{8[4]}$. Females patients were found to having higher TSH level as compared to males but it was statistically not significant. In contrast to this, in Asian population, Mansoor $\mathrm{R}$ et $\mathrm{al}^{[18]}$. in her study concluded significantly higher TSH level among male population than female population amongst primary hypothyroid cases. Meng $\mathrm{Z}$ et $\mathrm{al}^{[12]}$. On Chinese population found higher TSH level in females than male population.

\section{Conclusion}

Hypothyroidism remains an important clinical entity which may present with non specific symptomatology and may remain undiagnosed in population. Subclinical hypothyroidism makes an important subgroup in this clinical spectrum. Its association with other co morbid clinical conditions and its role in pathophysiology of other diseases makes hypothyroidism important for early diagnosis and proper management

\section{Acknowledgement}

The contribution of the staff of the Department of Medicine in the success of this study is highly appreciated.

\section{References}

1. Hollowell JG, Staehling NW, Flanders WD, Hannon WH, Gunter EW, Spencer CA, Braverman LE .Serum TSH, T(4), and thyroid antibodies in the United States population (1988 to 1994): National Health and Nutrition Examination Survey (NHANES III). J Clin Endocrinol Metab. 2002 Feb; 87(2):489-99.

2. Hoogendoorn EH, Hermus AR, de Vegt F, Ross HA, Verbeek AL, Kiemeney LA, Swinkels DW, Sweep FC, denHeijer .Thyroid function and prevalence of antithyroperoxidase antibodies in a population with borderline sufficient iodine intake: influences of age and sex. Clin Chem. 2006 Jan; 52(1):104-11.

3. http://www.ias.ac.in/currsci/oct252000/n\%2 0kochupillai.PDF .

4. Unnikrishnan AG, Kalra S, Sahay RK, Bantwal G, John M, Tewari N. Prevalence of hypothyroidism in adults: An epidemiological study in eight cities of India. Indian J Endocrinol Metab 2013; 17:647-52

5. M. Dörr and H. Völzke. Cardiovascular morbidity and mortality in thyroid dysfunction. Minerva Endocrinol. 2005 Dec;30(4):199-216

6. Chaker L, Bianco AC, Jonklaas J, Peeters RP. Hypothyroidism. Lancet. 2017;390 (10101):1550-1562. 
7. https://www.nhp.gov.in/disease/noncommunicable-disease/obesity

8. Usha Menon V, Sundaram KR, Unnikrishnan AG, Jayakumar RV, Nair V, Kumar H. High prevalence of undetected thyroid disorders in an iodine sufficient adult South Indian population. J Indian Med Assoc 2009; 107:72-7

9. Gaitonde DY, Rowley KD, Sweeney LB. Hypothyroidism: An update. S Afr Fam Pract 2012;54:384-90.

10. Khandelwal D, Tandon N. Overt and subclinical hypothyroidism: Who to treat and how. Drugs 2012;72:17-33

11. Xu, R., Huang, F., Zhang, S. et al. Thyroid function, body mass index, and metabolic risk markers in euthyroid adults: a cohort study. BMC EndocrDisord 19, 58 (2019).

12. Meng Z, Liu M, Zhang Q, et al. Gender and Age Impacts on the Association Between Thyroid Function and Metabolic Syndrome in Chinese. Medicine (Baltimore). 2015;94(50):e2193

13. Sethi B, Barua S, Raghavendra MS, Gotur J, Khandelwal D, Vyas U, et al. The thyroid registry: Clinical and hormonal characteristics of adult Indian patients with hypothyroidism. Indian J Endocrinol Metab. 2017;21:302-7.

14. Delemer B, Aubert JP, Nys P, Landron F, Bouée S. An observational study of the initial management of hypothyroidism in France: The ORCHIDÉE study. Eur J Endocrinol 2012;167:817-23.

15. Nair A, jayakumari c, Jabbar PK, Raizada Nishant, Gopi A. Prevalence and Associations of Hypothyroidism in Indian Patients with Type 2 Diabetes Mellitus. Journal of thyroid Research.

Volume 2018, Article ID 5386129, 7 pages

16. A. Papazafiropoulou, "Prevalence of thyroid dysfunction among greek Type 2 diabetic patients attending an outpatient clinic," Journal of Clinical Medicine Research, vol. 2, no. 2, pp. 75-78, 2010.
17. D. H. Akbar, M. M. Ahmed, and J. AlMughales, "Thyroid dysfunction and thyroid autoimmunity in Saudi type 2 diabetics," Acta Diabetologica, vol. 43, no. 1, pp. 1418, 2006.

18. Comparison of TSH, T4 and T3 Levels in Primary Hypothyroidism in relation to Gender and age in a Tertiary Care Hospital Ann. Pak. Inst. Med. Sci. 2011; 7(4): 186190. 